\title{
THE BIOLOGY OF PURPURA LAPILLUS. PART II. GROWTH
}

\author{
By Hilary B. Moore, Ph.D. \\ Bermuda Biological Station, Bermuda
}

(Text-figs. I-6)

In a previous paper (Moore, 1936) an account was given of certain variations in the shape and colour of the shell in Purpura, and it was pointed out that these variations are apparently controlled by diet. It was shown that growth ceases at the onset of sexual maturity, and at the same time other changes such as the thickening of the edge of the shell take place. It was shown also that both the proportion of the population exhibiting these changes, and the average size at which they occur, vary considerably from one locality to another, this variation also being apparently correlated with the nature of the animal's diet. The present paper consists of a study of the growth of the shell and soft parts and an attempt to show whether the observed differences in size at sexual maturity in different populations are to be accounted for by differences in the growth rate during the growing phase.

The growth rate of this species is difficult to determine for several reasons. In the first place, as will be shown later (Moore, I938, p. 67), the young and the adults live in different habitats, thus rendering it impossible to obtain a representative sample of the whole population. Even were this possible, the animal breeds throughout the year, so that its size distribution does not show year groups from which growth can be determined. I was therefore forced to use a method of marking individual shells, which involved the marking of large numbers, their release on the shore, and the subsequent recapture at intervals of the small proportion which could be found. If a true picture is to be obtained of growth under normal conditions it is essential that the growth period under observation should be passed in the natural habitat on the shore; but the very small shells could not be found again after they had been marked, and the difficulties of marking them were considerable. In practice therefore it was found necessary to determine the growth of the very small sizes in a laboratory tank, and to assume that the results so obtained were at any rate some indication of what the growth would have been under normal conditions. By linking these figures with those for larger animals living under natural conditions on the shore an approximate picture of the total growth of the animal has been obtained.

The young Purpura were obtained from egg capsules brought in from the shore when on the point of hatching, or, on one occasion, from eggs laid in a tank in the laboratory. They were kept in sea water in finger bowls until they 
hatched, when they were transferred to stones well covered with the polychaete Spirorbis borealis and free from algae and sponges. The stones were placed in a tank in which tides consisting of $8 \frac{1}{4} \mathrm{hr}$. immersion and $4 \frac{1}{4} \mathrm{hr}$. emersion were maintained electrically, and the tank was screened from too bright light to avoid excessive algal growth. The young Purpura lived well in such a habitat on a diet of Spirorbis, and showed little tendency to climb out

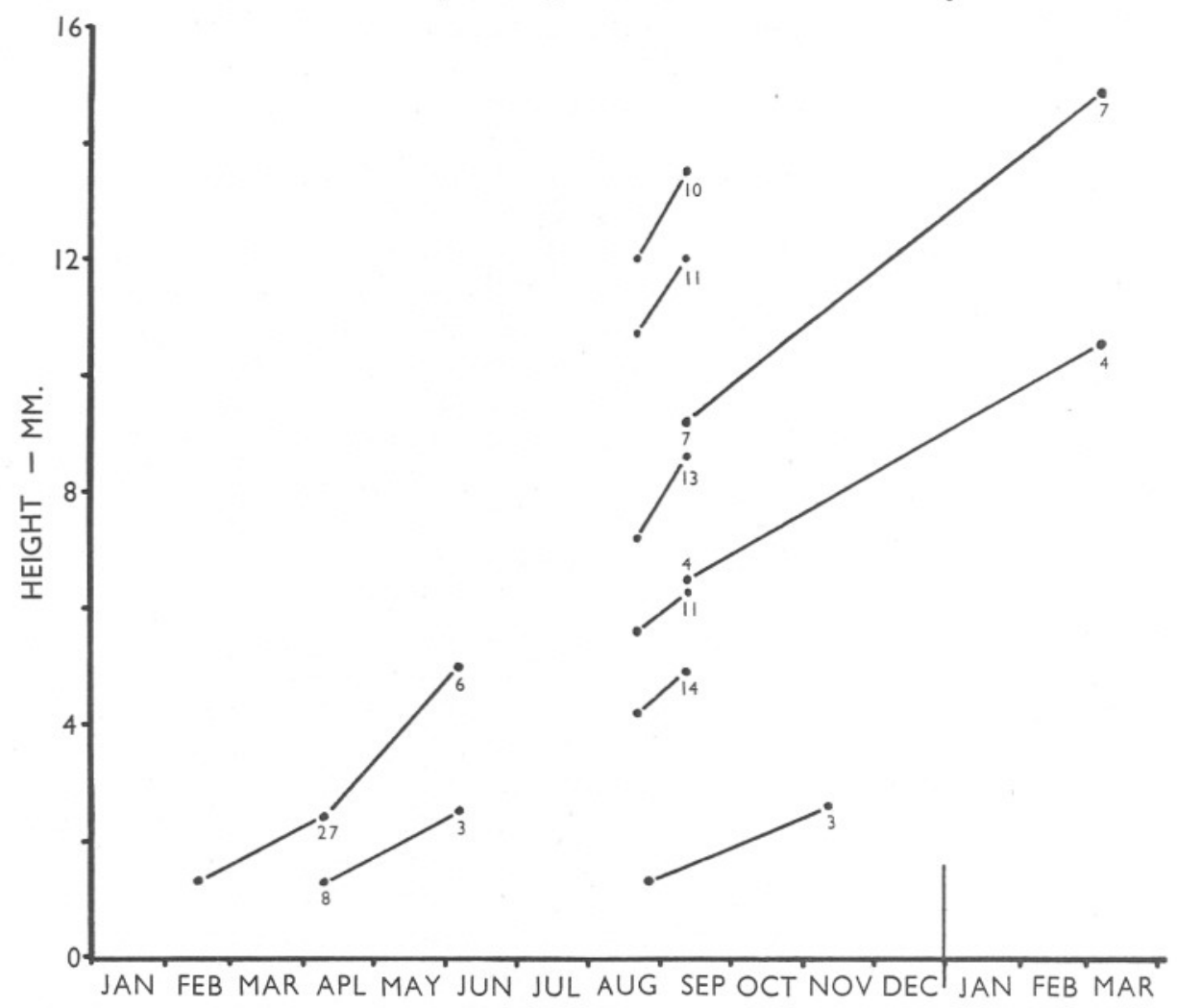

Fig. I. Growth of batches of young Purpura in a tidal tank at Plymouth. Figures indicate numbers of individuals. Height at hatching approximately $\mathrm{I} \cdot 3 \mathrm{~mm}$.

of the water as they do when no tide is supplied. It was found, however, that the duration of the tide was of little consequence so long as the animals were uncovered at intervals. In addition to the above experiments, a few very small Purpura were brought in from the shore and their shells painted with cellulose paint, so that new growth appeared as clean shell. As there was a suggestion of a normal change of diet with increasing size (see Moore, I938, p. 67), some stones covered with small Balanus balanoides were included as an alternative diet.

The results from these experiments are brought together in Fig. I. The series is incomplete, and the numbers of individuals are small, but the results 
may at least be taken as suggesting a growth of from Io to $\mathrm{I} 5 \mathrm{~mm}$. in the first year. Laboratory conditions are probably very much closer to normal for these small Purpura, which live in sheltered crevices and under stones, than they would be for the larger animals which live in the open, and whose feeding is more dependent on weather conditions. Colton (I9I6) has attempted to estimate the growth of this species at Mount Desert Island from the number of rings on the shell, believing that these rings are formed each winter. $\mathrm{He}$ adduces no evidence to prove this, and as he makes no mention of the important matter of cessation of growth at sexual maturity, his results must remain open to doubt. If, however, his assumptions are correct, his figure of I I-I $5 \mathrm{~mm}$. high at the first winter is comparable with the results obtained at Plymouth.

Drake's Island, in Plymouth Sound, was used for the main field experiments on the growth of the larger sizes. The method of marking was similar to that described for Littorina littorea (Moore, I937, p. 723), the lip of the shell being notched with a carborundum wheel, and the apex of the shell dipped in cellulose paint. In September I934, 2745 such marked shells were released on Drake's Island, on the same spot from which they were collected. Of these, the sex of 995 was determined and indicated by a different colour of paint, but as no difference of growth rate was found in the two sexes, and as it was later realized that growth occurs only while the animal is sexually immature, it was decided to combine the results from all the marked animals. The living shells were recaptured at intervals and taken back to the laboratory for measurement of growth. During this process, care was taken to keep them cool, and they were returned to the shore as soon as possible, either the same or the next day. The numbers of growing shells recaptured, together with the amounts of growth, are shown in Fig. 2. This figure also shows the results for a further I500 shells which were released in May I935 a short way from the first group, the numbers of the first group recaptured having by then dropped to so low a figure as to necessitate replacements.

The method of calculating the amount of increase in height of a shell corresponding to an observed increment to the lip has already been described for Littorina littorea (Moore, I937, p. 727), and is applicable in the same way to Purpura once the necessary constants and their variation with size of shell have been determined for the population in question. The shells, when brought in to the laboratory, were sorted into millimetre groups according to their height, and the increment to the lip of the shell measured for each individual. From these figures the mean increment of height, and hence the mean initial height at marking, were determined for each group. Owing to the gap between the last measurement of the first group of animals on March 27, and the release of the second group on May 8, it was necessary to calculate what the growth would have been during that period on the assumption that the rate was the same as during the previous period of January 9 to March 27, the value so obtained being then used as a base line for the growth of the second group. 
Although only growing, thin type, shells were used for the growth experiments, it is probable that the cessation of growth at the onset of sexual maturity is not instantaneous, so that at any rate some of the decrease in growth rate of the largest sizes is to be accounted for in this way. If we assume a height for the young shells of IO- $15 \mathrm{~mm}$. at the end of their first year, then they will grow about another II $\mathrm{mm}$. in their second year, and a slightly smaller growth rate in their third year would bring them to sexual maturity (at a mean size of

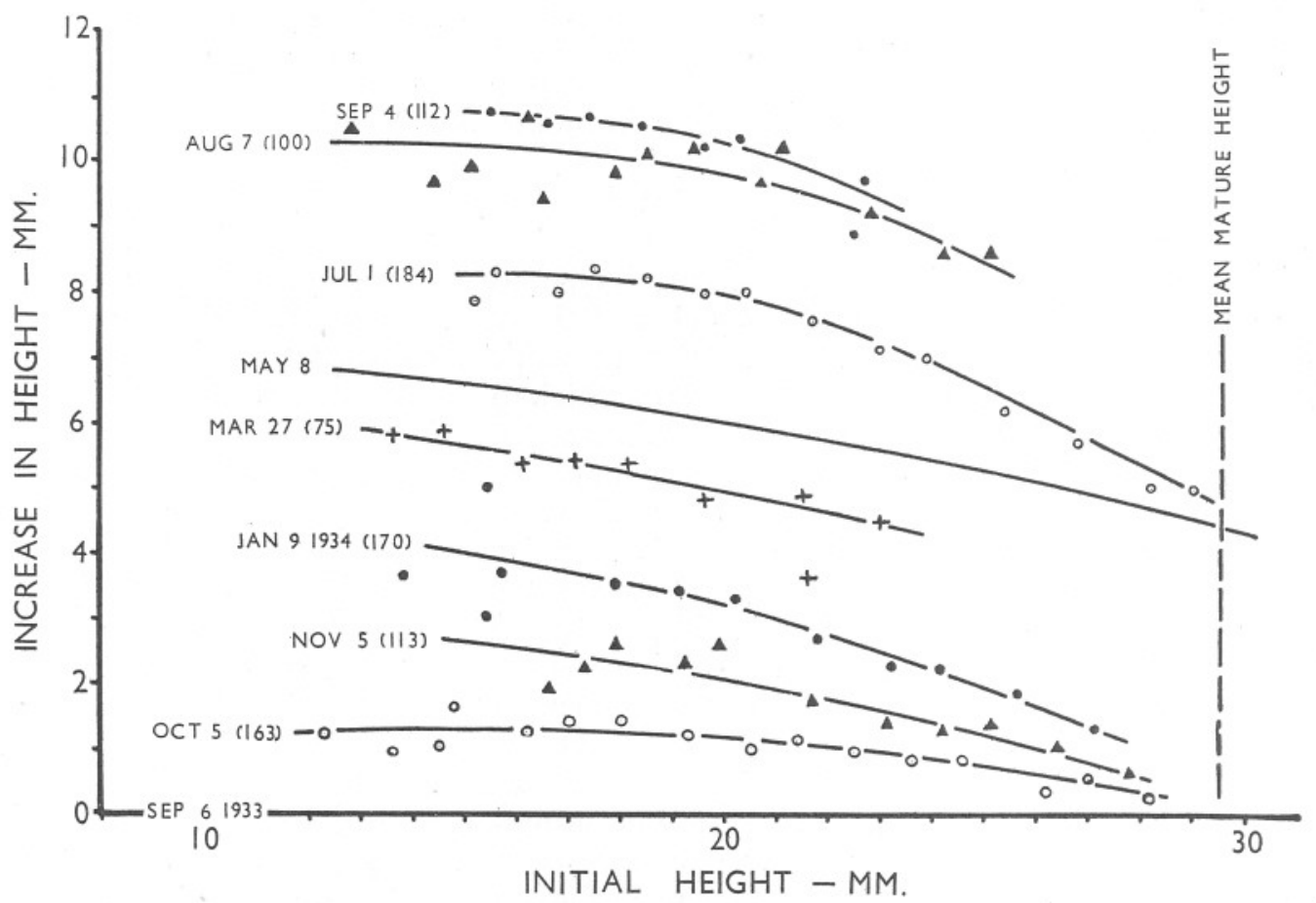

Fig. 2. Curves, at intervals up to one year, relating growth of large Purpura on the shore at Drake's Island, to initial height of shell. Each point represents the mean for a group of animals, and the total number for each curve is shown in brackets.

$29.5 \mathrm{~mm}$. for this population) at from $2 \frac{1}{2}$ to 3 years old. The error due to abnormal conditions in the young stages is unlikely to be more than \pm 6 months at the outside.

A small number of results are available also from shells kept on the shore at Port Erin, in the Isle of Man (Fig. 3); consecutive measurements of height were obtained from individual animals which had been marked with serially numbered silver tags wired to the lip of the shell. No data are available here for the growth rate of the young shells, but for the larger ones the average growth seems to be about 8-10 mm. per year. These curves show clearly the cessation of growth of the shell at sexual maturity. Colton's figures show an 
increase of two to five millimetres in height per year after the first year, but this may have included maturing or mature animals. Growth data for a short period during the summer from a number of localities in Devon and Cornwall (see below) show a growth of $0.5-4 \mathrm{~mm}$. per hundred days, the localities having been chosen to represent extremes of certain environmental characters.

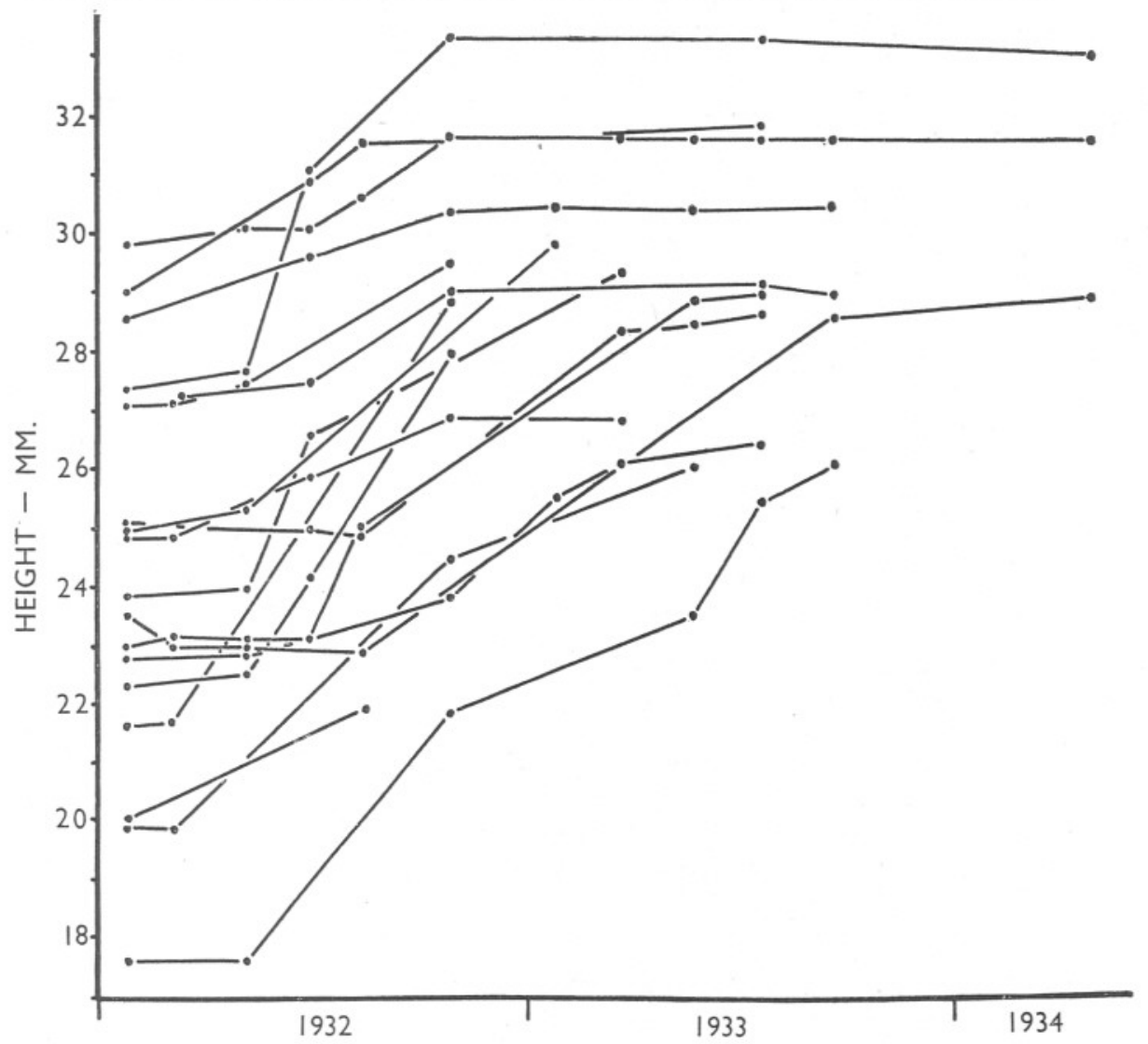

Fig. 3. Growth of individual Purpura on the shore at Port Erin, Isle of Man.

In comparing populations of Purpura from different localities, it was found (Moore, I936) that there was a definite tendency for those which had fed on a diet of Mytilus edulis, in contradistinction to one of barnacles, to attain sexual maturity, with cessation of shell growth, at a greater size, but for there to be a smaller proportion of the mature, non-growing phase in the population. The percentage of these non-growing shells varied from o to $98 \%$, which seemed too wide a range to be accounted for by hastening or delay of maturity unless this were correlated with a considerable variation in growth rate. In the hope of testing the latter point, samples were taken in the summers of 1935 and 
I936 from various selected localities in the west of England, marked in the usual way, and released in the places from which they were collected. After approximately three months these animals were recaptured, and the amounts of new shell growth measured. To obtain an adequate picture of the local growth conditions it would be essential to know the growth rate of all sizes of shells, but it was clearly impossible in the time available to deal with any but the larger sizes which could be found again on the shore. It would also have been desirable to work a larger number of localities, but the labour involved would have been too great. The principal characteristics of the populations and localities are shown in Table I. The localities are shown in the maps in my paper of 1936, where fuller details of the other characteristics are also given. The mean thick type height is the height at sexual maturity; the waveexposure scale ranges from $0=$ complete shelter, to $100=$ exposure to all winds from all quarters; the abundance of Mytilus ranges from $0=$ absent to $++++=$ very abundant.

\section{TABLE I}

$\begin{array}{lcccc}\text { Locality } & \begin{array}{c}\text { Mean thick } \\ \text { type height } \\ \text { (mm.) }\end{array} & \begin{array}{c}\text { Percentage of } \\ \text { thick type in } \\ \text { population }\end{array} & \begin{array}{c}\text { Wave } \\ \text { exposure }\end{array} & \begin{array}{c}\text { Abundance } \\ \text { of Mytilus }\end{array} \\ \text { Porthcurno } & \text { I8.9 } & 88 \cdot 6 & 9 & 0 \\ \text { Wanson Mouth } & 19 \cdot 9 & 89 \cdot 7 & 55 & + \\ \text { Bedruthan Steps } & 24 \cdot 6 & 6 \cdot 9 & 5 \mathrm{I} & ++++ \\ \text { Trebarwith Sands } & 27 \cdot 0 & 4 \cdot 0 & 12 & +++ \\ \text { Salthouse } & 27 \cdot 4 & 92 \cdot 6 & 54 & ++++ \\ \text { Biddle Head, Salcombe } & 28 \cdot 7 & 8 \mathrm{r} \cdot 8 & 6 & + \\ \text { Duckpool } & 29 \cdot 4 & 3 \cdot 6 & 45 & ++++ \\ \text { Drake's Island } & 29 \cdot 5 & 54 \cdot 7 & 0 & ++\end{array}$

The results obtained are shown in Fig. 4, and unfortunately they are inconclusive so far as the original problem is concerned. It is true that the Purpura from Biddle Head, Salcombe, which attain the large size at maturity of $28.7 \mathrm{~mm}$., also show the highest growth rate, while Wanson Mouth with the lowest growth rate shows the small size at maturity of $19.9 \mathrm{~mm}$. It is possible that this is significant, but the localities with intermediate mature heights show very varying growth rates, and Porthcurno, which attains an even smaller height at maturity than Wanson Mouth, has not nearly so low a growth rate, at least in the sizes used in the experiment. More detailed experiments would be necessary to clear up these points, but certain facts of value emerge from the experiments. In the first place the rates of growth in different localities are very different. Individuals of two centimetres high from Salcombe, for example, grow at ten times the rate of those of similar height from Wanson Mouth. The other noteworthy point is the lack of constancy in the relation of growth rate to size of shell, some populations increasing in growth rate with increasing size while others decrease. This is perhaps to be accounted for by variations in the relative values of the food supply in the young, Spirorbis-fed, stages, and the older, Mytilus- or barnacle-fed, stages in the different localities. 
The seasonal variation in tissue weight was determined in material from Misery Point, at the mouth of the river Yealm. Samples of the thick and thin types were taken at intervals and sorted into millimetre groups. Twenty indi-

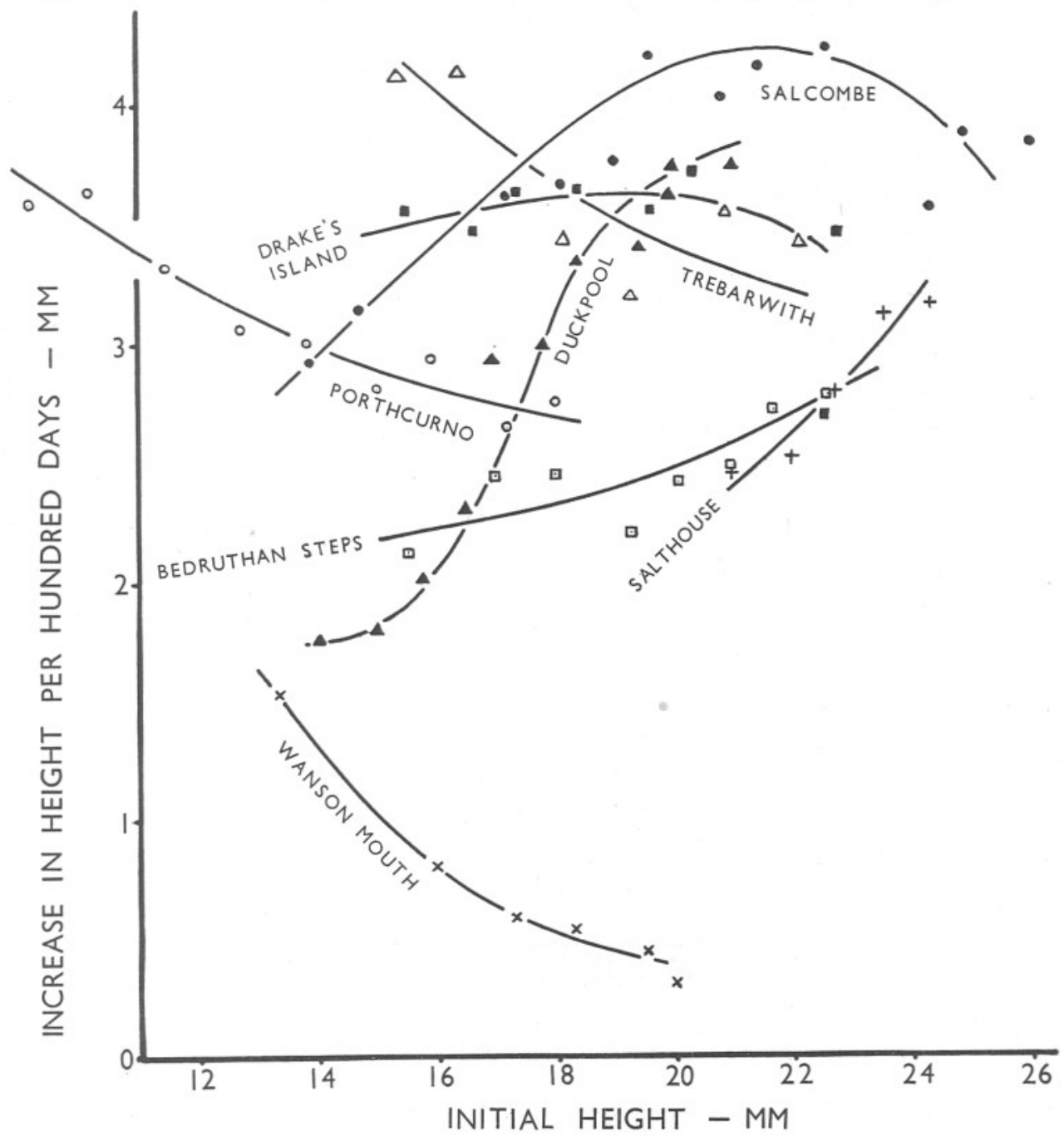

Fig. 4. The relation of growth to initial height in Purpura from different localities for a short period during the summer.

viduals from each group were then dropped into boiling water for a minute, removed from their shells, and both animals and shells dried to a constant weight in a boiling water oven. The question of shell weight was dealt with in a previous paper, and it was found that it showed no seasonal variation. In 
the thin-shelled immature animals, no significant seasonal variation in the tissue weight was found either, but the mature animals showed a considerable variation. Fig. 5 shows the seasonal changes in tissue weight of a Purpura $25.5 \mathrm{~mm}$. in height, which is the mean size for mature shells for this locality. As will be seen, the tissue weight drops rapidly from October to the beginning of April, and then rises again up to July, when observations ceased. This drop

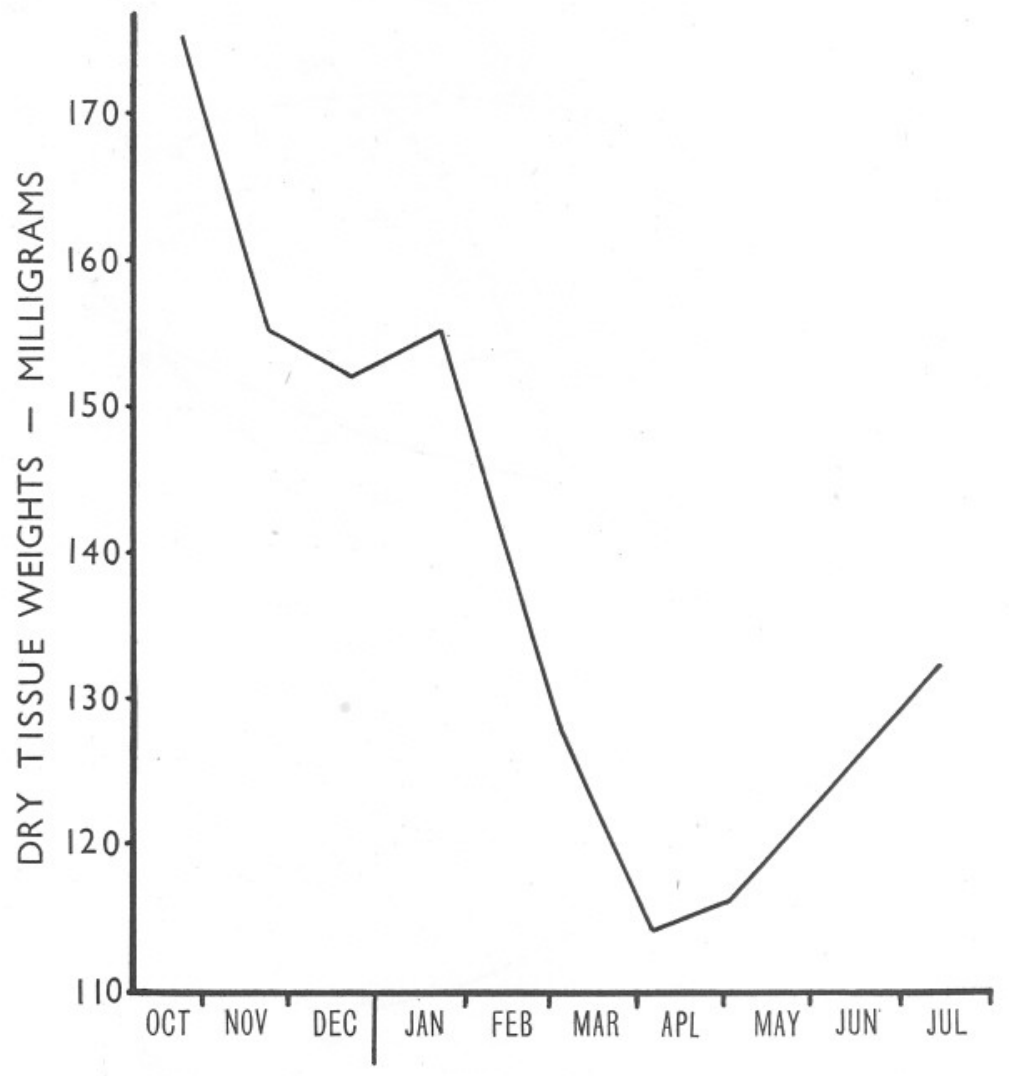

Fig. 5. Seasonal variation in tissue weight of mature (non-growing) Purpura, $25.5 \mathrm{~mm}$. high, at Misery Point, Yealm.

in weight may be caused by spawning, or by inability of the animal to obtain adequate nourishment during the winter months when the weather is too stormy for it to come out onto the open rocks to obtain its food. This latter explanation is unlikely, however, as the locality is well sheltered from the open sea, and no such winter drop in weight is shown by the larger immature animals feeding on the same diet and side by side with those that were mature. Yet another possibility is that the drop in weight is not directly due to the loss of ova or sperm, but to cessation of feeding during the period when the 
animals congregate in crevices to deposit their eggs. In any case, however, the drop in weight appears to be associated in some way with spawning. Pelseneer ( 1935, p. 445) quotes Peach as giving January to April as the principal spawning season of this species, and Garstang as giving January to April and September. Colton (I916) says that the young are hatched throughout the greater part of the summer, but most in August, and, allowing for their taking four months to hatch, as stated by Pelseneer (1935, p. 527), they would have been laid about

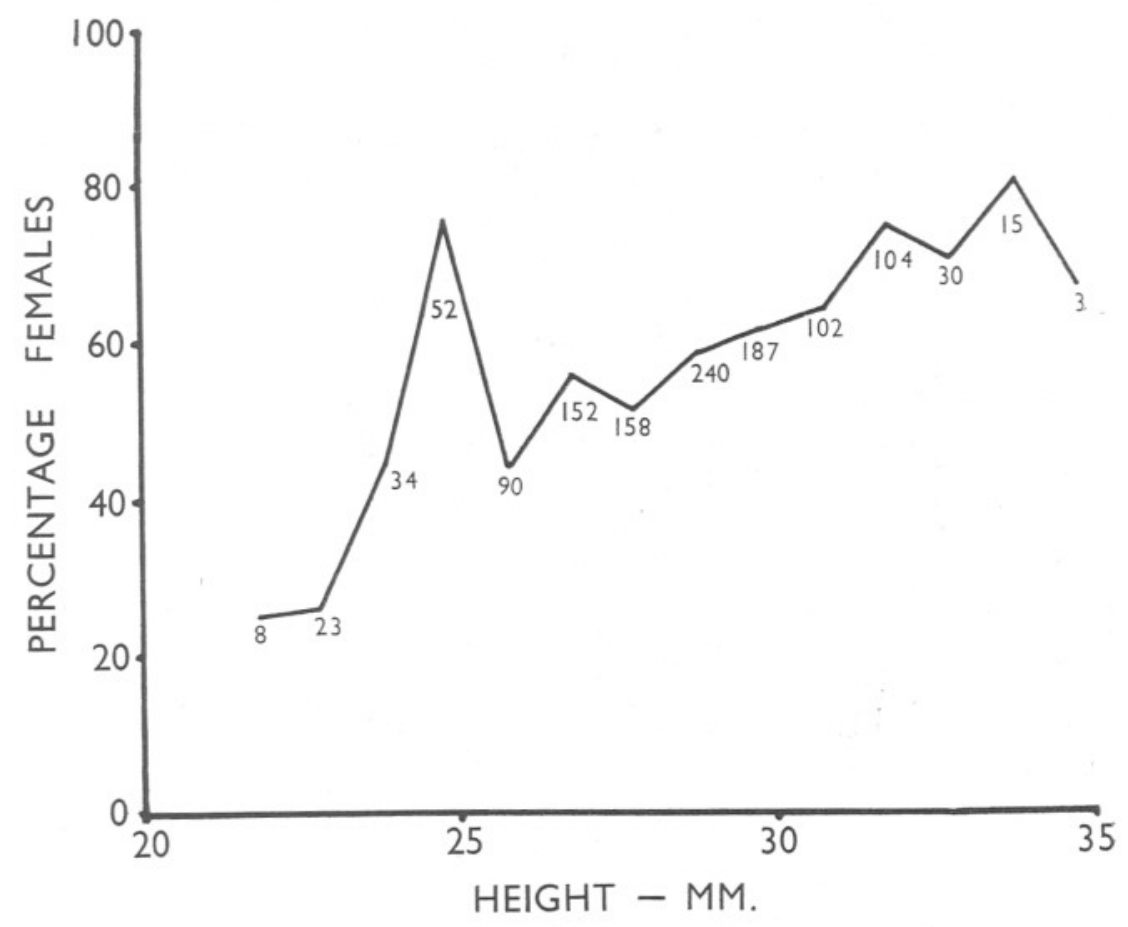

Fig. 6. Variation in the percentage of females in relation to size, in a sample of Purpura from Drake's Island. Figures indicate numbers examined.

April. In the Plymouth neighbourhood, although egg capsules are to be found throughout the year, they seem to be most abundant in the early summer, and the tissue weight curves suggest that the main spawning period is during the winter and spring.

Although the experiments with marked shells failed to show any difference in the rates of growth of males and females, a test was made to see whether the two sexes matured at the same size. The material was collected from Drake's Island in July 1935, and II95 individuals of the mature, thick type, were examined. Sex was determined by the presence or absence of a penis. The size distribution for each sex was then determined in millimetre groups. Females were more abundant in the ratio of 700 to 498, and, as shown in Fig. 6, the 
proportion of females increases in the larger sizes. This increase could not be accounted for by protandrous hermaphroditism, since growth ceases at maturity in both sexes, and must be due to some inherent difference in growth rate or age at maturity of the two sexes. Actually this increase chiefly affects those individuals whose size departs far from the mean, the mean sizes of the two sexes being $28.77 \pm 0.088 \mathrm{~mm}$. for the females, and $28.18 \pm 0.105 \mathrm{~mm}$. for the males, the difference, $0.59 \pm 0.137 \mathrm{~mm}$., being small but significant. Pelseneer also (1935, pp. 4I4-I5) notes the high proportion of females in this species, and that the proportion increases with age.

In conclusion I wish to express my great indebtedness to all those who have assisted in the collection of this material, and in particular the staff of the Plymouth Laboratory, Dr A. Gibson, Mr J. R. Bruce, and Messrs W. Searle and C. Haughton.

\section{REFERENCES}

Colton, H. S., I9I6. On some varieties of Thais lapillus in the Mount Desert region, a study of individual ecology. Proc. Acad. Nat. Sci. Philadelphia, Vol. Lxvir, pp. $440-54$.

MOoRE, H. B., I936. The biology of Purpura lapillus. I. Shell variation in relation to environment. Fourn. Mar. Biol. Assoc., Vol. xxI, pp. 6I-89.

- 1937. The biology of Littorina littorea. Part I. Growth of the shell and tissues, spawning, length of life and mortality. Fourn. Mar. Biol. Assoc., Vol. xxI, pp. 72 I42.

- I938. The biology of Purpura lapillus. Part III. Life history and relation to environmental factors. Fourn. Mar. Biol. Assoc., Vol. xxiII, pp. 67-74.

Pelseneer, P., I935. Essai d'éthologie zoologique d'après l'étude des mollusques, 662 pp. Brussels. 